\title{
Estrutura de mercado e poder de barganha de agroindústrias sucroalcooleiras do estado de São Paulo, Brasil
}

\section{Market structure and bargaining power at sugarcane industries in the state of São Paulo, Brazil}

\author{
Mayara B da Costa ${ }^{1}$, Lívia M. Brumatti ${ }^{\star}$ e Ana Claudia G. Borges 3 \\ IItaú Unibanco Holding S/A; \\ 2 UNESP Univ. Estadual Paulista - Campus de Rio Claro, Instituto de Geociências e Ciências Exatas (IGCE), Departamento de Geografia, CEP: 13506 - 900 , Rio Claro - SP, Brasil: \\ 3UNESP Univ. Estadual Paulista - Campus de Jaboticabal e de Rio Claro, Faculdade de Ciências Agrárias e Veterinárias, Departamento de Economia Rural, CEP: 14884 -900, Jaboticabal - SP, \\ Brasil. \\ ( ${ }^{\star} E$-mail: livia.brumatti@hotmail.com) \\ http://dx.doi.org/10.19084/RCA15010
}

Recebido/received: 2015.02.06

Aceite/accepted: 2015.12 .07

\section{R E S U M O}

Ao longo do desenvolvimento da atividade sucroalcooleira, observam-se períodos de concentração do mercado que afetam a dinâmica do setor. Assim, objetiva-se caracterizar as estruturas de mercado e o poder de barganha das agroindústrias sucroalcooleiras do estado de São Paulo, na safra de 2007/08. A partir de fontes secundárias, estabeleceram-se raios de atuação de $100 \mathrm{~km}$ e 25,1 km para as agroindústrias e por microrregião. As estruturas de mercado mais observadas nas microrregiões e no raio de 100 km, são as de oligopólio pouco concentrado e monopólio e, no raio de 25,1km, são as de monopólio e oligopólio pouco concentrado.

Palavras-chave: Estado de São Paulo, Estrutura de mercado, poder de barganha, setor sucroalcooleiro.

\begin{abstract}
A B S T R A C T
In the curse of sugarcane activity, it was observed periods of market concentration that affect the dynamics of the sector. Thus, this study aims to characterize the market structures and the bargaining power of the sugarcane industries of São Paulo, at the harvests of 2007/08. From secondary sources, actuation radius of $100 \mathrm{~km}$ and $25.1 \mathrm{~km}$ were established for the sugar cane industries and for micro-region. The market structures most observed in the micro-regions, and within a radius of $100 \mathrm{~km}$, are the little concentrated oligopoly structures and the monopoly and, in the radius of $25.1 \mathrm{~km}$, the monopoly and the little concentrated oligopoly.
\end{abstract}

Keywords: bargaining power, market structure, sugarcane sector, state of São Paulo.

\section{INTRODUÇÃO}

Diversas foram as transformações ocorridas no setor sucroalcooleiro desde o início de sua produção no país. Para exemplificar algumas destas mudanças, destacam-se: na década de 1930, o surgimento do Instituto do Açúcar e Álcool (IAA), em 1933, quando se inicia a regulamentação do setor (Belik, 1985); em 1975, a criação do Programa Nacional do Álcool (PROÁLCOOL), o qual desenvolveu sobremaneira a produção do álcool para combustível veicular, alterando significativamente a dinâmica do setor; e, na década de 1990, o processo de desregulamentação do setor, a partir de mudanças na economia brasileira, com a adoção do ideário Neoliberal que altera a dinâmica da economia do país e deste setor (Barros e Moraes, 2002).

Nesse último período supracitado, as decisões principais do setor deixam de estar sob 
responsabilidade do Estado e passam a ser dos agentes privados. Estes agentes, para permanecerem no setor, sob esta nova dinâmica, adotam estratégias competitivas, como, as de diversificação da produção, diferenciação de produto, minimização do custo sem prejuízo à qualidade, desenvolvimento de produto (P\&D), fusões e aquisições (F\&A), crescimento, modernização, entre outras (Pasin e Neves, 2002; Vian, 2003). O processo de F\&A das agroindústrias sucroalcooleiras, bem como o surgimento de novas agroindústrias alterou significativamente a estrutura de mercado ${ }^{1}$ das mesmas (Pasin e Neves, 2002), contribuindo, principalmente, para um processo de concentração ${ }^{2}$ de mercado no setor (Borges e Costa, 2009). Observa-se, também no período, um processo de abertura da economia do país, que permitiu a entrada de empresas estrangeiras, tecnologicamente desenvolvidas, na produção do setor sucroalcooleiro. Além disso, a partir de 2000, o mercado internacional apresentou crescimento considerável, o que possibilitou maior capitalização das usinas através de investimentos de estrangeiros. Isto estimulou mudanças na forma de gestão das empresas, substituindo a administração familiar pela profissional (Siqueira e Castro Jr., 2010).

Essas, entre outras, mudanças contribuíram para a ampliação da produção do setor sucroalcooleiro e do processo de concentração e centralização dos capitais, interferindo, consequentemente, na quantidade e no tamanho das agroindústrias brasileiras (Szmrecsányi, 2000; Borges e Costa, 2013).

Esse processo de redução do número de agroindústrias e do respectivo aumento de suas estruturas produtivas (Szmrecsányi, 2000), afeta, sobremodo,

\footnotetext{
As estruturas de mercado são "modelos que captam aspectos inerentes de como os mercados estão organizados" (Troster, 2004), destacando interações relevantes da demanda e da oferta. Nas estruturas consideram-se aspectos como: porte das empresas, diferenciação de produtos, transparência do mercado, barreiras à entrada e à saída, dentre outros (Troster, 2004). Ferguson (1974) aponta a existência de duas estruturas principais que representam situações extremas e opostas no que se refere à atomização e à concentração da produção: a concorrência perfeita e o monopólio. As demais estruturas existentes, segundo o mesmo autor, são derivações dos modelos principais.

2 O processo de concentração da atividade produtiva está atrelado ao processo de concentração do capital proposto por Marx (1996), no qual "[...] toda acumulação torna-se meio de uma nova acumulação" (Marx, 1996, p. 245). Todos os mecanismos de concentração e centralização do capital (absorção das pequenas pelas grandes empresas), propostos por Marx, contribuem para a tendência de oligopolização ou monopolização empresarial (Kon, 1999).
}

o poder de barganha ${ }^{3}$ (poder de negociação da troca) entre as agroindústrias sucroalcooleiras e os produtores de cana-de-açúcar, visto que a concentração das agroindústrias pode representar uma alteração na competitividade do setor, gerando oportunidades para essas empresas estabelecerem preços diferentes, e contribuindo para uma desigualdade na relação entre os poucos compradores e os muitos produtores (Cavalheiro, 2014). Além disso, é importante ressaltar que nesse processo de obtenção da cana-de-açúcar, há a produção própria pela agroindústria, diminuindo a dependência desta frente à cana proveniente de terceiros. Observa-se, também, na relação de compra e venda da cana-de-açúcar a existência de especificidade de ativos (baseada na teoria de Economia de Custos de Transação; Williamson, 1996), como o temporal e o locacional. $\mathrm{O}$ ativo temporal pode ser identificado com a ressalva feita por Baccarin et al. (2009), de que a cana deve ser processada até quarenta e oito horas após a colheita, para não comprometer o rendimento industrial. Essas características impactam na negociação de aquisição da cana-de-açúcar e assim no poder de barganha das partes.

Se considerar os ativos específicos destacados, tem-se a distribuição espacial geográfica, das agroindústrias e dos produtores, como um elemento relevante para definir o campo de atuação de cada agente e, portanto, a estrutura de mercado desses agentes, o grau de concentração de mercado e a intensidade do poder de barganha.

Assim, a partir da distribuição espacial geográfica das agroindústrias e das unidades de produção agrícola (UPAs) de cana-de-açúcar, do estado de São Paulo - Brasil, tem-se como objetivo caracterizar a estrutura e a concentração de mercado e o poder de barganha das agroindústrias sucroalcooleiras, na safra de 2007/08. Para esse propósito, foram utilizados métodos estatísticos para essa caracterização, considerando como campo de análise as microrregiões do estado de São Paulo e os mercados com dois raios de atuação distintos: 25,1 km e 100 km. Microrregião é um conjunto de municípios, contíguos e contidos na mesma Unidade da

3 A capacidade de uma das partes impor seus desejos em uma transação é o que se denomina poder de barganha. Este poder, por sua vez, pode ser expresso em diversas situacões, sendo as mais importantes os seus extremos: poder absoluto (estrutura em monopólio) e ausência de poder (estrutura de concorrência perfeita). Apesar da importância dessas situações, o caso mais intrigante é o poder observado nas estruturas de oligopólio, nas quais os comportamentos dos agentes estão interligados, o que pode ocasionar conflitos (Azevedo, 1996). 
Federação, definidos com base em características do quadro natural, da organização da produção e de sua integração (IBGE, 2010). Essas distâncias consideradas foram eleitas a partir de textos que se referem a esse assunto, entre eles: o texto de Borges (2010) que identifica, em sua pesquisa, a distância de até $100 \mathrm{~km}$ para a aquisição da cana-de-açúcar; e o relatório da CONAB (2008) que define 25,1 km como a distância média.

Por fim, deve-se mencionar que este trabalho está estruturado em quatro partes, sendo a primeira esta introdução, a segunda aborda os métodos utilizados para análise dos dados, a terceira destaca as discussões e resultados identificados e a última apresenta as considerações finais dos autores sobre o tema abordado.

\section{MATERIAL E MÉTODOS}

Esta pesquisa pretende-se descritiva (Marconi e Lakatos, 2003), na medida em que busca o delineamento, ainda que relativo, das características de três variáveis: estrutura de mercado; concentração de mercado; e poder de barganha. Assim, busca-se o entendimento dessas variáveis a partir das agroindústrias sucroalcooleiras, no ato de compra da cana-de-açúcar. Além disso, devido à utilização de métodos estatísticos para a análise dos dados, a pesquisa também pode ser classificada como quantitativa (Malhotra, 2006). A análise dos dados é realizada mediante estabelecimento de categorias, da tabulação, da análise estatística dos dados e da interpretação dos mesmos (Gil 1999). Primeiramente, fez-se coleta de dados secundários, para a safra de 2007/08, quanto: à localização das agroindústrias sucroalcooleiras no estado de São Paulo, no Departamento de Cana-de-açúcar e Agroenergia do Ministério da Agricultura, Pecuária e Abastecimento (MAPA); ao volume de processamento de cana-de-açúcar das agroindústrias, na União da Indústria de Cana-de-açúcar do estado de São Paulo (UNICA); e à identificação das unidades de produção agrícola (UPAs) de cana-de-açúcar, por município, no Censo das Unidades de Produção Agropecuária do estado de São Paulo (LUPA) (dados obtidos a partir de relatório censitário, realizado a cada 10 anos). A partir dessa coleta, identificou-se o nome e a localização de 177 agroindústrias cadastradas no MAPA, no período de análise. Na base da UNICA identificou-se o nome e o volume de processamento de cana-de-açúcar de 150 agroindústrias. A partir destas duas bases, consideraram-se aquelas agroindústrias que constavam nas duas listagens, relacionando o município de atuação da agroindústria (MAPA) e o volume de processamento de cana-de-açúcar (UNICA, 2011). É importante destacar que este período foi escolhido, pois foi o único que apresentava todos os dados necessários para análise.

Em seguida, as UPAs de cana-de-açúcar e as agroindústrias sucroalcooleiras foram agrupadas por microrregião. Essas microrregiões são consideradas como um primeiro mercado de

Quadro 1 - Exemplificação da quantidade e da distância das agroindústrias por microrregião - Raio de 25,1 km ou de100 km. Fonte: Costa (2012)

\begin{tabular}{|c|c|c|c|c|}
\hline \multicolumn{2}{|c|}{$\begin{array}{l}\text { Quantidade de } \\
\text { Agroindústrias }\end{array}$} & \multicolumn{3}{|c|}{ Microrregião 1} \\
\hline & Raio de $25,1 \mathrm{~km}$ & $\begin{array}{l}\text { Agroindústria } \\
\text { A }\end{array}$ & $\begin{array}{l}\text { Agroindústria } \\
\text { B }\end{array}$ & $\begin{array}{l}\text { Agroindústria } \\
\text { C }\end{array}$ \\
\hline \multirow{3}{*}{ 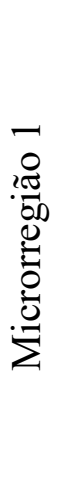 } & Agroindústria A & & $\begin{array}{c}\text { Distância em } \\
\text { quilometragem } \\
\text { de A e B }\end{array}$ & $\begin{array}{c}\text { Distância em } \\
\text { quilometragem } \\
\text { de A e C }\end{array}$ \\
\hline & Agroindústria $\mathrm{B}$ & $\begin{array}{c}\text { Distância em } \\
\text { quilometragem } \\
\text { de B e A }\end{array}$ & & $\begin{array}{c}\text { Distância em } \\
\text { quilometragem } \\
\text { de B e C }\end{array}$ \\
\hline & Agroindústria $\mathrm{C}$ & $\begin{array}{c}\text { Distância em } \\
\text { quilometragem } \\
\text { de C e A }\end{array}$ & $\begin{array}{c}\text { Distância em } \\
\text { quilometragem } \\
\text { de C e B }\end{array}$ & \\
\hline
\end{tabular}


análise. Porém, as especificidades de ativos e os custos de transporte definem um raio de atuação para as agroindústrias, em 25,1 km e $100 \mathrm{~km}$. Estes raios de atuação podem conter ou não outras agroindústrias disputando a compra de cana-deaçúcar das UPAs estabelecidas na localidade. Com isso, estes raios são delimitações de mercados mais restritos que a microrregião.

Para a determinação da distância de atuação das agroindústrias na compra de cana-de-açúcar foi utilizado o software GEO-Tiggra (Cálculo de Distância Geodésia), considerando os raios estabelecidos. Assim, para efeito de análise, são consideradas apenas as agroindústrias que atuavam em uma mesma microrregião e, posteriormente, dentro dos raios estabelecidos, Quadro 1.

Assim, é possível obter, considerando-se a área de atuação das agroindústrias, o primeiro mercado que é o das microrregiões e, depois, os mercados mais restritos (segunda análise - M1, M2 e M3) para os raios de 25,1 km e $100 \mathrm{~km}$ (Figura 1).

Após, faz-se a análise do grau de concentração das agroindústrias sucroalcooleiras por microrregião e para os raios de atuação das agroindústrias. Para tal, utilizou-se o índice de concentração de Hirschaman-Herfindahl $(\mathrm{HH})^{4}$ que é definido, segundo Resende e Boff (2002), como:

$H H=\sum_{i=1}^{n} s_{i}^{2}$

Sendo si a participação de cada empresa no mercado, definida pela quantidade de cana-de-açúcar processada pela agroindústria $(\mathrm{Xi})$ sobre a quantidade total de cana-de-açúcar processada por todas as agroindústrias $(X)$, para os diferentes mercados de análise.

$s_{i}=\frac{X_{i}}{X}$

\footnotetext{
4 Cabe considerar que esse índice é muito utilizado em estudos recentes sobre concentração de mercado, tais como em: Sediyama et al. (2013), para as indústrias processadoras de soja; Luft e Zilli (2013) na análise da oferta de crédito; Zaniol e Oliveira (2013) para a indústria cervejeira. Justifica-se sua utilização, pois ao elevar cada parcela de mercado ao quadrado atribui-se maior peso às empresas relativamente maiores (Sediyama et al., 2013).
}

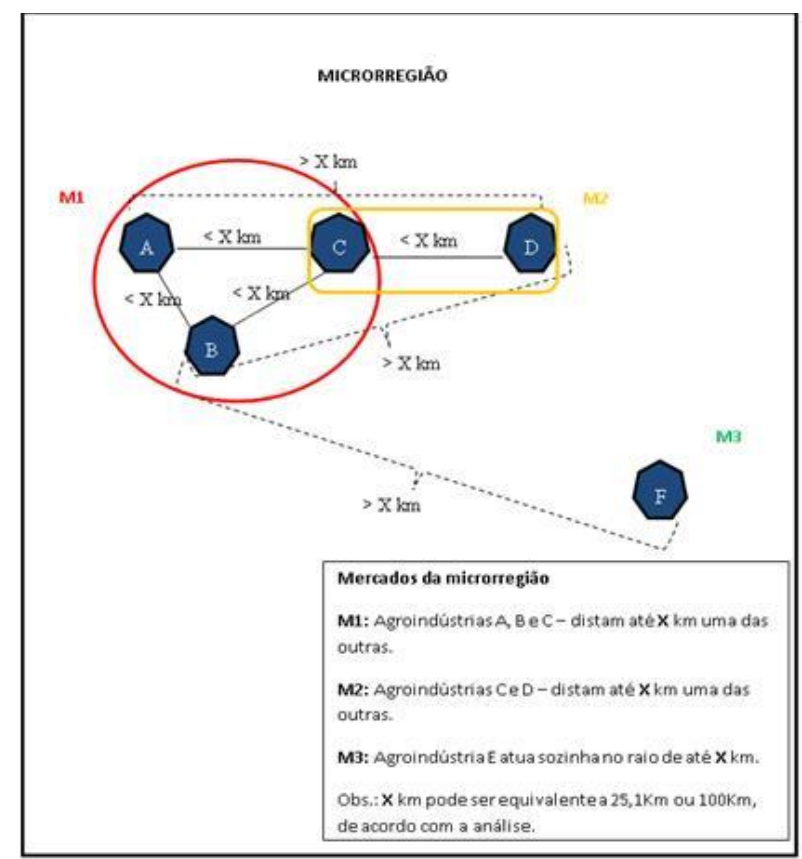

Figura 1 - Apresentação da forma de análise da microrregião e de definição dos mercados. Fonte: Costa (2012).

Quadro 2 - Classificação da Estrutura de mercado e da Concentração a partir do Índice HH. Fonte: Elaborado a partir de Resende e Boff (2002)

\begin{tabular}{|c|c|}
\hline Estrutura de Mercado & Índice HH \\
\hline Monopólio & $\mathrm{HH}=1$ \\
\hline Oligopólio Altamente Concentrado & $0,5<\mathrm{HH}<1$ \\
\hline Oligopólio Médio & $\mathrm{HH}=0,5$ \\
\hline Oligopólio Pouco Concentrado & $0<\mathrm{HH}<0,5$ \\
\hline Concorrência Perfeita & $\mathrm{HH}=0$ \\
\hline
\end{tabular}

$\mathrm{O}$ índice de concentração $\mathrm{HH}$ varia entre $\mathbf{0} \mathrm{e}$ 1, sendo que o valor 1 representa a situação de extrema concentração (monopólio) e o valor $\mathbf{0}$, nenhuma concentração, que é representada pela estrutura de mercado em concorrência perfeita (Quadro 2).

Cabe salientar, ainda, que o índice $\mathrm{HH}$ dificilmente apresenta o nível $\mathbf{0}$ e, portanto, assume-se que em um nível de classificação em que $\mathrm{HH}$ for maior que $\mathbf{0}$ e menor que $\mathbf{0 , 1}$, a estrutura de mercado é de oligopólio muito pouco concentrado, tendendo à concorrência perfeita. A partir desta análise de concentração é possível dimensionar o poder de barganha das agroindústrias sucroalcooleiras, de acordo com suas respectivas estruturas de mercado. Na situação de monopólio tem-se o poder de barganha extremo, na de concorrência 
perfeita há a inexistência de este poder e na de oligopólio o pode de barganha depende do grau de concentração.

Cabe destacar, ainda, que a existência de apenas uma agroindústria caracteriza a concentração extrema. Quanto mais próximo de $\mathbf{1}$ for o índice $\mathrm{HH}$, maior deve ser o poder de barganha das agroindústrias frente aos produtores de cana-de-açúcar. $\mathrm{O}$ número reduzido de unidades agroindústrias em determinada região caracteriza uma situação de oligopólio. E, devido à grande quantidade de produtores de cana-de-açúcar no estado de São Paulo, admitiu-se uma situação de concorrência perfeita para eles em todas as microrregiões analisadas.

\section{RESULTADOS E DISCUSSÃO}

Para a identificação das estruturas de mercado e do poder de barganha das agroindústrias sucroalcooleiras frente aos produtores de cana-de-açúcar consideram-se as microrregiões do estado de São Paulo, como os primeiros mercados de análise. $\mathrm{O}$ estado possui 63 microrregiões, das quais apenas 38 apresentam, pelo menos, uma agroindústria sucroalcooleira em atividade na safra de 2007/08 (Quadro 3). Nesta Tabela estão destacados, também, os números de municípios, agroindústrias e UPAs sucroalcooleiras para cada microrregião (MAPA, 2008; LUPA, 2009), bem como seus respectivos Índices de Concentração $(\mathrm{HH})$, o qual possibilita classificar a estrutura de mercado e, assim, identificar o poder de barganha das agroindústrias por microrregião.
Na Figura 1, pode-se observar o número de microrregiões por tipo de estrutura de mercado, a partir do Quadro 3. Das microrregiões, 19 (50\%) apresentam uma estrutura de oligopólio pouco concentrado, o que pode representar baixo poder de barganha, das agroindústrias sucroalcooleiras frente aos produtores, na transação de compra da cana-de-açúcar, das quais se destacam São José do Rio Preto, Jaboticabal e Presidente Prudente. No que se refere às estruturas de oligopólio altamente concentrados identificam-se sete microrregiões (18\%), o que garante às mesmas, um alto poder de barganha nas relações com os produtores.

O Índice HH 1 evidencia a situação de monopólio, o que é observado em 10 microrregiões (26\%), ou seja, garante à única agroindústria destas microrregiões, um poder de barganha extremamente forte frente aos produtores de cana-de-açúcar Pode-se visualizar, ainda, que a microrregião de Barretos é a única que apresenta uma estrutura de oligopólio médio, o que acarreta um poder de barganha médio. Outra microrregião de destaque é a de Ribeirão Preto, a qual apresenta 18 agroindústrias no total de seu território. $\mathrm{O}$ alto número de agroindústrias e o fato de muitas delas estarem sediadas nos mesmos municípios, pode significar concorrência intensa entre elas. Assim, com um índice de 0,0828, essa microrregião se estrutura em um oligopólio pouco concentrado, tendendo à concorrência perfeita.

Como ressaltado, as agroindústrias não atuam na microrregião como um todo, devido à alta especificidade da cana-de-açúcar (Azevedo, 1996).

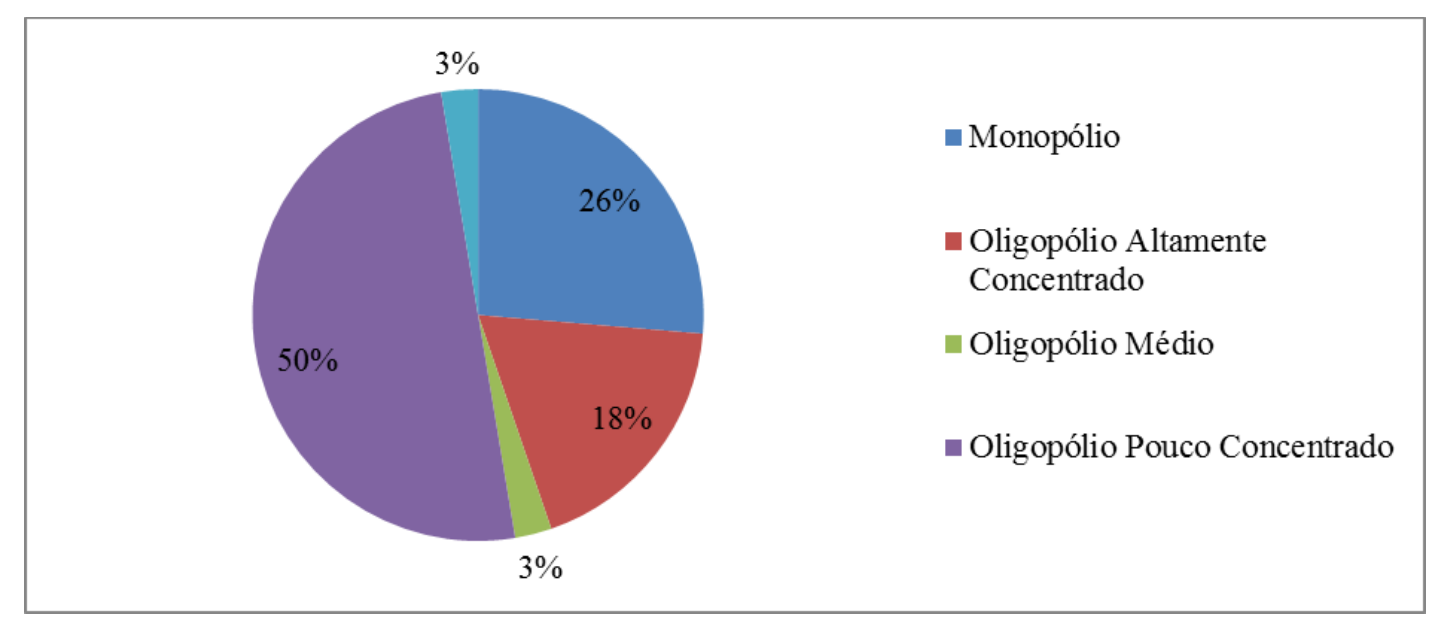

Figura 2 - Distribuição das microrregiões por tipo de estrutura de mercado. 
Quadro 3 - Estrutura de mercado das agroindústrias sucroalcooleiras por microrregião do estado de São Paulo

\begin{tabular}{|c|c|c|c|c|c|}
\hline Microrregião & $\begin{array}{l}\mathbf{N}^{\circ} \\
\text { Muni- } \\
\text { cípios }\end{array}$ & $\begin{array}{l}\mathrm{N}^{0} \text { Agro- } \\
\text { indústrias } \\
\text { Sucro- } \\
\text { alcooleiras }\end{array}$ & $\begin{array}{c}\mathbf{N}^{\mathbf{0}} \\
\text { UPAs }\end{array}$ & $\begin{array}{c}\text { Índice } \\
\text { HH }\end{array}$ & Classificação \\
\hline Auriflama & 9 & 1 & 1.411 & 1 & \multirow{10}{*}{ Monopólio } \\
\hline Batatais & 6 & 1 & 1.640 & 1 & \\
\hline Campinas & 16 & 1 & 1.089 & 1 & \\
\hline Fernandópolis & 11 & 1 & 1.188 & 1 & \\
\hline Franca & 10 & 1 & 1.365 & 1 & \\
\hline Itapetininga & 5 & 1 & 1.073 & 1 & \\
\hline Lins & 8 & 1 & 1.628 & 1 & \\
\hline Rio Claro & 6 & 1 & 1.786 & 1 & \\
\hline Tupã & 7 & 1 & 680 & 1 & \\
\hline Votuporanga & 9 & 1 & 1.532 & 1 & \\
\hline Bauru & 21 & 3 & 3.283 & 0,5496 & \multirow{7}{*}{$\begin{array}{l}\text { Oligopólio Altamente } \\
\text { Concentrado }\end{array}$} \\
\hline Ituverava & 5 & 2 & 1.763 & 0,5114 & \\
\hline Moji mirim & 7 & 2 & 722 & 0,7197 & \\
\hline Nhandeara & 9 & 2 & 2.180 & 0,725 & \\
\hline Novo Horizonte & 6 & 2 & 2.136 & 0,5537 & \\
\hline Pirassununga & 4 & 3 & 1.435 & 0,5097 & \\
\hline São Carlos & 6 & 2 & 1.643 & 0,8194 & \\
\hline Barretos & 3 & 2 & 955 & 0,5 & Oligopólio Médio \\
\hline Adamantina & 14 & 4 & 1.808 & 0,2742 & \multirow{19}{*}{$\begin{array}{l}\text { Oligopólio Pouco } \\
\text { Concentrado }\end{array}$} \\
\hline Andradina & 11 & 5 & 1.995 & 0,2202 & \\
\hline Araçatuba & 7 & 6 & 1.329 & 0,2124 & \\
\hline Araraquara & 15 & 7 & 3.759 & 0,1708 & \\
\hline Assis & 16 & 7 & 2.909 & 0,2009 & \\
\hline Avaré & 8 & 3 & 1.390 & 0,3884 & \\
\hline Birigui & 18 & 4 & 3.228 & 0,3217 & \\
\hline Catanduva & 13 & 4 & 2.874 & 0,27 & \\
\hline Dracena & 10 & 3 & 1.292 & 0,3634 & \\
\hline Jaboticabal & 17 & 8 & 5.819 & 0,1474 & \\
\hline Jaú & 12 & 6 & 4.355 & 0,2855 & \\
\hline Limeira & 8 & 5 & 1.469 & 0,2774 & \\
\hline Ourinhos & 18 & 7 & 1.321 & 0,2318 & \\
\hline Piracicaba & 12 & 7 & 3.984 & 0,2239 & \\
\hline Presidente Prudente & 30 & 5 & 5.529 & 0,2772 & \\
\hline São João da Boa Vista & 14 & 4 & 1.958 & 0,3063 & \\
\hline São Joaquim da Barra & 9 & 6 & 2.858 & 0,1894 & \\
\hline São José do Rio Preto & 29 & 10 & 5.743 & 0,1543 & \\
\hline Tatuí & 9 & 3 & 2.030 & 0,4568 & \\
\hline Ribeirão Preto & 16 & 18 & 3.857 & 0,0828 & $\begin{array}{c}\text { Oligopólio Pouco } \\
\text { Concentrado (Tendendo à } \\
\text { concorrência perfeita) }\end{array}$ \\
\hline Total & 434 & 150 & \multicolumn{3}{|l|}{87.016} \\
\hline
\end{tabular}


Assim, Borges (2010) aponta que há casos em que a distância pode alcançar $100 \mathrm{~km}$, mas a CONAB (2008) estabelece um raio médio de $25,1 \mathrm{~km}$ para a obtenção de cana-de-açúcar. Neste sentido, têm-se as Tabelas 2 e 3, apresentando os mercados das agroindústrias sucroalcooleiras para os raios de $100 \mathrm{~km}$ e 25,1 km, respectivamente, em cada microrregião, bem como a classificação das estruturas de mercado, a partir do índice de $\mathrm{HH}$.

Considerando o raio de atuação de 100 km (Borges, 2010), observam-se as seguintes situações indicadas no Quadro 4.

É importante destacar que a maioria das agroindústrias se localiza a menos de $100 \mathrm{~km}$ umas das outras. Assim, a observação dos dados permite concluir que as estruturas de mercado para o raio de atuação de 100 km são as mesmas que as observadas na análise do território para o mercado Microrregião, exceto para o caso da microrregião de São José do Rio Preto. Esta apresenta cinco diferentes arranjos entre as agroindústrias, ou seja, cinco mercados. Nesses arranjos, consideram-se os mercados com todas as unidades agroindústrias, bem como mercados em que se exclui uma unidade e arranjos com sete unidades. Para exemplificar isto, é possível considerar a agroindústria H (Quadro 5), que dista mais de $100 \mathrm{~km}$ de outras (A, D e F), mas apresenta uma distância inferior a $100 \mathrm{~km}$ das agroindústrias B, C, E, G, I e J. Essa proximidade entre as agroindústrias indica, assim, a existência de concorrência intensa com baixo poder de barganha.

Vale ressaltar que, apesar da metade das microrregiões apresentarem um índice de concentração entre 0,1 e 0,5 , isto é, possuírem baixo poder de barganha no que se referem as suas estruturas de mercado, outros fatores contribuem significativamente na definição deste poder, como é o caso da possibilidade de produção de cana-de-açúcar pelas próprias agroindústrias processadoras em terras próprias ou de arrendamento.

No mercado definido pelo raio de atuação de 25,1 km das agroindústrias (Quadro 6), pode-se observar a formação de mercados diversos dentro de uma mesma microrregião. Em outras palavras, neste tipo de análise é possível identificar estruturas diferentes das identificadas no território como um todo (Microrregião).
Verificam-se, no Quadro 6, estruturas em monopólio em 18 microrregiões, das quais quando analisadas, no mercado Microrregião (Quadro 3), apresentaram outras estruturas de mercado que não o de monopólio. Nesses mercados de 25,1 km, em situação de monopólio, estão localizados as microrregiões de: São José do Rio Preto (cinco mercados); São João da Boa Vista (quatro mercados); Ribeirão Preto, Presidente Prudente e Bauru (três mercados cada); São Carlos, Birigui, Barretos e Araraquara (dois mercados cada); e, com um mercado, tem-se São Joaquim da Barra, Piracicaba, Ourinhos, Limeira, Jaú, Avaré, Araçatuba, Andradina e Adamantina.

Outra característica relevante é a tendência de se ter oligopólio altamente concentrado em mercados em que existem apenas duas agroindústrias, sendo o índice mais próximo de um, quanto mais próxima for a distância entre as agroindústrias. Além disso, nas situações em que há duas ou mais agroindústrias e as mesmas estão localizadas em um único município, também se observa situação de oligopólio altamente concentrado, indicando a atuação conjunta dessas, porém com participações diferenciadas no processamento da cana-de-açúcar, como é o caso da microrregião de Nhandeara, Novo Horizonte e Pirassununga. Estas três microrregiões e Moji Mirim, Dracena e Tatuí apresentam a mesma estrutura de mercado observada na análise do mercado Microrregião (Quadro 3).

Cabe destacar que a microrregião de Ribeirão Preto é a única que apresenta a estrutura de mercado em monopólio e oligopólio altamente concentrado, médio e pouco concentrado, para o raio de 25,1 km. Se desconsiderar as três agroindústrias que se encontram em situação de monopólio, identifica-se ainda um mercado de oligopólio médio (concorrência entre duas agroindústrias) um mercado de oligopólio altamente concentrado (concorrência entre duas agroindústrias) e cinco mercados em que a estrutura é a de oligopólio pouco concentrado. Neste último caso é possível identificar diferentes arranjos de agroindústrias: dois mercados com 11 unidades diferentes; dois mercados com 10 unidades distintas; e um mercado com três unidades.

Assim, admite-se que entre essas unidades agroindústrias há uma concorrência mais intensa do que em outros mercados, o que pode diminuir o poder de barganha delas frente aos produtores. No 
Quadro 4 - Estruturas de Mercado por Microrregião - Raio de 100 km

\begin{tabular}{|c|c|c|c|c|c|c|}
\hline \multirow[b]{3}{*}{ Microrregião } & \multirow[b]{3}{*}{$\begin{array}{l}\text { Quantidade de } \\
\text { agroindústrias }\end{array}$} & \multicolumn{5}{|c|}{ Estruturas de mercado das agroindústrias } \\
\hline & & \multirow[b]{2}{*}{ Monopólio } & \multicolumn{4}{|c|}{ Oligopólio } \\
\hline & & & $\begin{array}{c}\text { Altamente } \\
\text { Concentrado }\end{array}$ & Médio & $\begin{array}{c}\text { Pouco } \\
\text { Concentrado }\end{array}$ & $\begin{array}{c}\text { Pouco } \\
\text { Concentrado } \\
\text { Tendendo à } \\
\text { Concorrência } \\
\text { Perfeita }\end{array}$ \\
\hline Adamantina & 4 & & & & 1 & \\
\hline Andradina & 5 & & & & 1 & \\
\hline Araçatuba & 6 & & & & 1 & \\
\hline Araraquara & 7 & & & & 1 & \\
\hline Assis & 7 & & & & 1 & \\
\hline Auriflama & 1 & 1 & & & & \\
\hline Avaré & 3 & & & & 1 & \\
\hline Barretos & 2 & & & 1 & & \\
\hline Batatais & 1 & 1 & & & & \\
\hline Bauru & 3 & & 1 & & & \\
\hline Birigui & 4 & & & & 1 & \\
\hline Campinas & 1 & 1 & & & & \\
\hline Catanduva & 4 & & & & 1 & \\
\hline Dracena & 3 & & & & 1 & \\
\hline Fernandópolis & 1 & 1 & & & & \\
\hline Franca & 1 & 1 & & & & \\
\hline Itapetininga & 1 & 1 & & & & \\
\hline Ituverava & 2 & & 1 & & & \\
\hline Jaboticabal & 8 & & & & 1 & \\
\hline Jaú & 6 & & & & 1 & \\
\hline Limeira & 5 & & & & 1 & \\
\hline Lins & 1 & 1 & & & & \\
\hline Moji Mirim & 2 & & 1 & & & \\
\hline Nhandeara & 2 & & 1 & & & \\
\hline Novo Horizonte & 2 & & 1 & & & \\
\hline Ourinhos & 8 & & & & 1 & \\
\hline Piracicaba & 7 & & & & 1 & \\
\hline Pirassununga & 3 & & 1 & & & \\
\hline PresidentePrudente & 5 & & & & 1 & \\
\hline Ribeirão Preto & 18 & & & & & 1 \\
\hline Rio Claro & 1 & 1 & & & & \\
\hline São Carlos & 2 & & 1 & & & \\
\hline São Joãoda Boa Vista & 4 & & & & 1 & \\
\hline São Joaquim daBarra & 6 & & & & 1 & \\
\hline SãoJosédo RioPreto & 10 & & & & 5 & \\
\hline Tatuí & 3 & & & & 1 & \\
\hline Tupã & 1 & 1 & & & & \\
\hline Votuporanga & 1 & 1 & & & & \\
\hline
\end{tabular}


Quadro 5 - Quantidade e distância das agroindústrias na microrregião de São José do Rio Preto - Raio de 100 km. Fonte: Costa (2012)

\begin{tabular}{|c|c|c|c|c|c|c|c|c|c|c|c|}
\hline \multirow{2}{*}{\multicolumn{2}{|c|}{$\begin{array}{l}\text { Quantidade de } \\
\text { Agroindústrias } \\
\text { Raio de } 100 \mathrm{~km}\end{array}$}} & \multicolumn{10}{|c|}{ Agroindústrias da Microrregião de São José do Rio Preto } \\
\hline & & & & \multirow{2}{*}{$\begin{array}{l}\mathrm{C} \\
99,3\end{array}$} & \multirow{2}{*}{$\frac{D}{26,1}$} & \multirow{2}{*}{$\frac{E}{26,1}$} & \multirow{2}{*}{$\begin{array}{l}\mathrm{F} \\
55,4\end{array}$} & \multirow{2}{*}{$\frac{G}{52,2}$} & \multirow{2}{*}{$\frac{\mathrm{H}}{117,8}$} & \multirow{2}{*}{$\frac{\mathrm{I}}{75,1}$} & \multirow{2}{*}{$\frac{\mathrm{J}}{74,5}$} \\
\hline \multirow{10}{*}{ 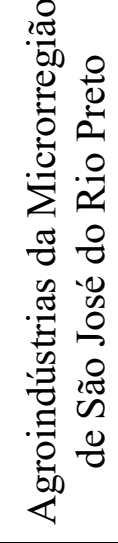 } & A & & & & & & & & & & \\
\hline & $\mathrm{B}$ & 98 & 8 & 16,6 & 87,9 & 87,9 & 102,5 & 77,7 & 24,8 & 31,8 & 47,1 \\
\hline & $\mathrm{C}$ & 99,3 & 16,6 & 8 & 84,7 & 84,7 & 112,1 & 87,2 & 38,8 & 25,5 & 60,5 \\
\hline & $\mathrm{D}$ & 26,1 & 87,9 & 84,7 & 8 & 42,7 & 77 & 66,2 & 110,1 & 59,2 & 77,7 \\
\hline & $\mathrm{E}$ & 38,2 & 64,3 & 69,4 & 42,7 & 9 & 47,1 & 26,7 & 81,5 & 50,3 & 36,9 \\
\hline & $\mathrm{F}$ & 55,4 & 102,5 & 112,1 & 77 & 47,1 & 5 & 24,8 & 112,1 & 96,1 & 58,6 \\
\hline & $\mathrm{G}$ & 52,2 & 77,7 & 87,2 & 66,2 & 26,7 & 24,8 & 9 & 87,9 & 72,6 & 34,4 \\
\hline & $\mathrm{H}$ & 117,8 & 24,8 & 38,8 & 110,1 & 81,5 & 112,1 & 87,9 & 5 & 57,3 & 53,5 \\
\hline & $\mathrm{I}$ & 75,1 & 31,8 & 25,5 & 59,2 & 50,3 & 96,1 & 72,6 & 57,3 & 9 & 54,8 \\
\hline & $\mathrm{J}$ & 74,5 & 47,1 & 60,5 & 77,7 & 36,9 & 58,6 & 34,4 & 53,5 & 54,8 & 9 \\
\hline
\end{tabular}

entanto, isto pode não ser aferido, pois há a possibilidade de produção própria de cana-de-açúcar e de proximidade entre as agroindústrias de um mesmo grupo, o que diminui a disputa por cana.

\section{CONSIDERAÇÕES FINAIS}

Na análise da concentração por microrregiões, pôde-se identificar que $50 \%$ das microrregiões se encontram em situação de oligopólio pouco concentrado, $26 \%$ em monopólio, $18 \%$ em oligopólio altamente concentrado, $3 \%$ em oligopólio médio e, também, 3\% em oligopólio muito pouco concentrado tendendo à concorrência perfeita. Isto significa dizer que $53 \%$ das microrregiões apresentaram baixo poder de barganha frente aos produtores de cana (oligopólio pouco e muito pouco concentrado), ao passo que $44 \%$ delas possuíam alto poder de barganha na transação de compra da cana-de-açúcar (estruturas de monopólio e oligopólio altamente concentrado), para a safra 2007/08.

Para o raio de 100 km de atuação, os dados se aproximam do identificado na análise das estruturas do mercado Microrregião. Nas 38 microrregiões foram observados 44 mercados, dos quais 10 (23\%) em monopólio, sete (16\%) em oligopólio altamente concentrado, 25 (57\%) em oligopólio pouco concentrado e um mercado em oligopólio médio e em oligopólio pouco concentrado tendendo à concorrência perfeita. A maior parte das agroindústrias
(121 de 150) atua em mercados menos concentrados e com menor poder de barganha na relação com os produtores de cana.

Para a análise do mercado das agroindústrias, a partir do raio de atuação de $25,1 \mathrm{~km}$ em cada microrregião, observou-se 96 mercados nas $38 \mathrm{mi}-$ crorregiões, dos quais 45 (47\%) em monopólio, 23 (24\%) em oligopólio altamente concentrado, um mercado em oligopólio médio e 27 (28\%) em oligopólio pouco concentrado. Ainda para o mesmo raio, na microrregião de Ribeirão Preto, pôde-se identificar a ocorrência de várias possibilidades de estruturas de mercado, devido à grande quantidade de agroindústrias dentro da mesma microrregião.

Para o estudo de mercados, com raio de até 25,1 $\mathrm{km}$, foi possível constatar que as agroindústrias se encontram em mercados mais concentrados e, consequentemente, com maior poder de barganha frente aos produtores de cana-de-açúcar.

Vale destacar que este estudo considerou apenas o poder de barganha das agroindústrias a partir das suas estruturas de mercado, sendo importante observar, para a realização de estudos futuros, outros condicionantes do poder de barganha, bem como levar em consideração, a formação de grandes grupos entre as agroindústrias, as condições de transporte de cana-de-açúcar no território e as políticas de pagamentos da cana-de-açúcar propostas pelo setor. 
Quadro 6 - Estruturas de Mercado por Microrregião - Raio de 25,1 km

\begin{tabular}{|c|c|c|c|c|c|}
\hline \multirow{3}{*}{ Microrregião } & \multirow{3}{*}{$\begin{array}{c}\text { Quantidade } \\
\text { de } \\
\text { agroindústrias }\end{array}$} & \multicolumn{4}{|c|}{ Estruturas de mercado das agroindústrias } \\
\hline & & \multirow[b]{2}{*}{ Monopólio } & \multicolumn{3}{|c|}{ Oligopólio } \\
\hline & & & $\begin{array}{c}\text { Altamente } \\
\text { Concentrado }\end{array}$ & Médio & $\begin{array}{c}\text { Pouco } \\
\text { Concentrado }\end{array}$ \\
\hline Adamantina & 4 & 1 & & & 1 \\
\hline Andradina & 5 & 1 & 2 & & \\
\hline Araçatuba & 6 & 1 & 1 & & 2 \\
\hline Araraquara & 7 & 2 & 1 & & 2 \\
\hline Assis & 7 & & 1 & & 3 \\
\hline Auriflama & 1 & 1 & & & \\
\hline Avaré & 3 & 1 & 1 & & \\
\hline Barretos & 2 & 2 & & & \\
\hline Batatais & 1 & 1 & & & \\
\hline Bauru & 3 & 3 & & & \\
\hline Birigui & 4 & 2 & 1 & & \\
\hline Campinas & 1 & 1 & & & \\
\hline Catanduva & 4 & & 1 & & 2 \\
\hline Dracena & 3 & & & & 1 \\
\hline Fernandópolis & 1 & 1 & & & \\
\hline Franca & 1 & 1 & & & \\
\hline Itapetininga & 1 & 1 & & & \\
\hline Ituverava & 2 & & 1 & & \\
\hline Jaboticabal & 8 & & 1 & & 2 \\
\hline Jaú & 6 & 1 & 1 & & 2 \\
\hline Limeira & 5 & 1 & & & 1 \\
\hline Lins & 1 & 1 & & & \\
\hline Moji Mirim & 2 & & 1 & & \\
\hline Nhandeara & 2 & & 1 & & \\
\hline Novo Horizonte & 2 & & 1 & & \\
\hline Ourinhos & 8 & 1 & 5 & & 1 \\
\hline Piracicaba & 7 & 1 & & & 4 \\
\hline Pirassununga & 3 & & 1 & & \\
\hline Presidente Prudente & 5 & 3 & 1 & & \\
\hline Ribeirão Preto & 18 & 3 & 1 & 1 & 5 \\
\hline Rio Claro & 1 & 1 & & & \\
\hline São Carlos & 2 & 2 & & & \\
\hline São João da Boa Vista & 4 & 4 & & & \\
\hline São Joaquim da Barra & 6 & 1 & 1 & & 1 \\
\hline São José do Rio Preto & 10 & 5 & 3 & & 1 \\
\hline Tatuí & 3 & & & & 1 \\
\hline Tupã & 1 & 1 & & & \\
\hline Votuporanga & 1 & 1 & & & \\
\hline
\end{tabular}




\section{Nota}

O presente trabalho foi elaborado a partir de dados e informações levantados para a elaboração do
Trabalho de Conclusão de Curso de Mayara B. da Costa (2012), financiado pela Fundação de Amparo à Pesquisa do Estado de São Paulo (FAPESP).

\section{REFERÊNCIAS BIBLIOGRÁFICAS}

Azevedo, P.F. (1996) - Integração vertical e barganha. Tese de Doutoramento. Universidade de São Paulo, Brasil. 193 p.

Baccarin, J.G.; Gebara, J.J. e Rosada, A.A. (2009) - Avanço recente da concentração econômica sucroalcooleira no centro-sul do Brasil. Cadernos CERU, vol. 20, n. 2, p. 87-102.

Barros, G.S.C. e Moraes, M.A.F.D. (2002) - A desregulamentação do setor sucroalcooleiro. Revista de Economia Política, vol. 22, n. 2, p. 156-173.

Belik, W. (1985) - A tecnologia em um setor controlado: o caso da agroindústria canavieira em São Paulo. Cadernos de Difusão de Tecnologia, vol. 2, n. 1, p. 99-136.

Borges, A.C.G. (2010) - Estruturas de governança para a obtenção da cana-de-açúcar no setor sucroalcooleiro. In: XXIV Congreso Internacional de Economía Aplicada - ASEPELT 2010. Anais. Universidad Alicante Espanha, ASEPELT, p. 2302-2326.

Borges, A.C.G e Costa, V.M.H.M. (2009) - Fusões e aquisições no setor sucroalcooleiro pós desregulamentação. In: XXIX Encontro Nacional de Engenharia de Produção. Salvador - BA, Brasil.

Borges, A.C.G e Costa, V.M.H.M. (2013) - O processo de concentração e de centralização do capital e o financiamento da produção sucroalcooleira no Brasil. In: VI Simpósio Internacional de Geografia Agrária e VII Simpósio Nacional de Geografia Agrária. João Pessoa - PB, Brasil.

Cavalheiro, E. A. (2014) - The biofuel industry concentration in Brazil between 2005 and 2012. In: Padula et al. (Orgs.) - Liquid Biofuels: Emergence, Development and Prospects. Lecture Notes in Energy vol. 27 p. 73-91.

CONAB. Companhia Nacional de Abastecimento. (2008) - Perfil do setor do açúcar e do álcool no Brasil, situação observada em novembro de 2007. Brasília [citado 2012-11-10]. Disponível em: $<$ http://www.conab.gov.br/conabweb/download/safra/perfil.pdf >.

Costa, M.B. (2012) - Estrutura de mercado e poder de barganha das agroindústrias sucroalcooleiras no estado de São Paulo para a safra 2007/2008. Trabalho de Conclusão de Curso. Universidade Estadual Paulista "Júlio de Mesquita Filho", Brasil. 114 p.

Ferguson, C.E. (1974) - Microeconomia. 14 ed. Rio de Janeiro, Forense Universitária, 614 p.

Gil, A.C. (1999) - Métodos e técnicas de pesquisa social. 5. Ed. São Paulo, Editora Atlas, 206 p.

IBGE. Instituto Brasileiro de Geografia e Estatística. (2010) - Descrição das variáveis da amostra do Censo Demográfico 2010. Brasília [citado 2014-02-05]. Disponível em:

< http://www.ipea.gov.br/redeipea/images/pdfs/descricao_das_variaveis_censo_2010.pdf>.

Kon, A. (1999) - Economia industrial. 1. Ed. São Paulo, Editora Nobel, 212 p.

Luft, A. e Zilli, J.B. (2013) - Concentração de mercado: uma análise para a oferta de crédito pelo setor bancário brasileiro. Teoria e Evidência Econômica, vol. 19, n. 41, p. 150-172. http://dx.doi.org/10.5335/rtee.v0i41.3737

LUPA. Levantamento Censitário de Unidades de Produção Agrícola do Estado de São Paulo. (2009) Dados consolidados municipais 2007/08. Secretaria de Agricultura e Abastecimento, Instituto de Economia Agrícola, Coordenadoria de Assistência Técnica Integral. São Paulo [citado 2012-10-13]. Disponível em: $<$ http://www.cati.sp.gov.br/ projetolupa/ > .

Malhotra, N. (2006) - Pesquisa de marketing: uma orientação aplicada. 4. Ed. Porto Alegre, Editora Bookman, $720 \mathrm{p}$.

MAPA. Ministério da Agricultura, Pecuária e Abastecimento. (2015) - Departamento de Cana-de-açúcar e Agroenergia. Disponível em: <www.agricultura.gov.br/>.

Marconi, M.A. e Lakatos, E.M. (2003) - Fundamentos de metodologia científica. 5a Ed. São Paulo, Editora Atlas, $311 \mathrm{p}$.

Marx, K. (1996) - O capital: crítica da economia política. 24 Ed. Livro 1, [O processo de produção do capital], vol. 1. Rio de Janeiro, Editora Civilização Brasileira..

Pasin, R.M. e Neves, M. F. (2002) - Fusões, Aquisições e Internacionalização: o caso da agroindústria sucroalcooleira. Faculdade de Economia, Administração e Contabilidade da Universidade de São Paulo, São Paulo. 
Resende, M. e Boff, H. (2005) - Concentração industrial. In: Kupfer, D. e Hasenclever, L. (Orgs.) - Economia Industrial: fundamentos teóricos e práticos no Brasil. Rio de Janeiro, Editora Campus, p. 73-90.

Sediyama, A.F.; Castro Jr., L.G.; Calegario, C.L.L. e Siqueira, P.H.L. (2013) - Análise da estrutura, conduta e desempenho da indústria processadora de soja no Brasil no período de 2003 a 2010. Revista de Economia e Sociologia Rural, vol. 51, n. 1, p. 161-182. http://dx.doi.org/10.1590/S0103-20032013000100009

Siqueira, P.H.L. e Castro Jr. L. G. (2010) - Fusões e aquisições das unidades produtivas e da agroindústria de cana-de-açúcar no brasil e nas distribuidoras de álcool hidratado etílico. Revista de Economia e Sociologia Rural, vol. 48, n. 4, p.709-735. http://dx.doi.org/10.1590/S0103-20032010000400009

Szmrecsányi, T. (2000) - Apresentação. In: Ferraz, J.M.G. et al (Eds.) - Certificação socioambiental do setor sucroalcooleiro. São Paulo, Embrapa Meio Ambiente, p. 7-13.

Troster, R.L. (2004) - Estruturas de mercado. In: Gremaud, A.P. et al. (Eds.) - Manual de economia. 5. Ed. São Paulo, Editora Saraiva, p. 191-202.

UNICA. União da Agroindústria Canavieira de São Paulo. (2011) - Estatística. São Paulo [citado 2011, 08-13]. Disponível em: <http://www.unica.com.br/pages/estatisticas .asp.>.

Vian, C.E.F. (2003) - Agroindústria canavieira: estratégias competitivas e modernização. 1. Ed. Campinas, Editora Átomo, $216 \mathrm{p}$.

Williamson, O. (1996) - Introdução. In: Williamson, O. e Winter, S. (Orgs.) - La Natureza da Empresa: orígenes, evolução y desarollo. Fondo de Cultura Econômica, México, p. 9-28.

Zaniol, G.Z. e Oliveira, J.C. (2013) - Análise da concentração na indústria cervejeira brasileira no período entre 1989 e 2011. Revista Estudos do CEPE, n. 38, p. 42-65. 